\title{
Hemorrhagic Cystitis in Allogeneic Stem Cell Transplantation: A Role for Age and Prostatic Hyperplasia
}

Eugenio Galli ( $\nabla$ eug.galli@gmail.com )

Universita Cattolica del Sacro Cuore https://orcid.org/0000-0002-2839-916X

Federica Sorà

Universita Cattolica del Sacro Cuore

Luca Di Gianfrancesco

Fondazione Policlinico Universitario Agostino Gemelli IRCCS

Sabrina Giammarco

Fondazione Policlinico Universitario Agostino Gemelli IRCCS

Elisabetta Metafuni

Fondazione Policlinico Universitario Agostino Gemelli IRCCS

Maria Assunta Limongiello

Fondazione Policlinico Universitario Agostino Gemelli IRCCS

Idanna Innocenti

Fondazione Policlinico Universitario Agostino Gemelli IRCCS

Francesco Autore

Fondazione Policlinico Universitario Agostino Gemelli IRCCS

Luca Laurenti

Universita Cattolica del Sacro Cuore

Patrizia Chiusolo

Universita Cattolica del Sacro Cuore

Andrea Bacigalupo

Universita Cattolica del Sacro Cuore

Simona Sica

Universita Cattolica del Sacro Cuore

\section{Research Article}

Keywords: Allogeneic stem cell transplantation, hemorrhagic cystitis. prostatic hyperplasia

Posted Date: October 21st, 2021

DOl: https://doi.org/10.21203/rs.3.rs-866797/v1 
License: (c) (i) This work is licensed under a Creative Commons Attribution 4.0 International License. Read Full License

Version of Record: A version of this preprint was published at Supportive Care in Cancer on February 18th, 2022. See the published version at https://doi.org/10.1007/s00520-022-06916-8. 


\section{Abstract}

PURPOSE Hemorrhagic cystitis $(\mathrm{HC})$ is a frequent complication during allogeneic hematopoietic stem-cell transplantation (HSCT). HC worsen transplant outcomes and patients wellbeing in terms of pain, medicalization and need for supportive care. Deeper understanding of $\mathrm{HC}$ risk factors may contribute to focus on more intense prevention in high risk patients.

METHODS In this report we analyzed 237 consecutive patients who had received HSCT in order to identify possible risk factors for $\mathrm{HC}$ and their consequences, focusing on transplant- and gender-related risk factors.

RESULTS HC occurred in $17 \%$ of patients, with higher incidence in males ( $21 \%$ vs $11 \%, p=0.03)$. Risk factors for $\mathrm{HC}$ were age over 55 years, recipients male gender, mismatched-HLA, reduced intensity conditioning and cyclophosphamide-based graft versus host disease (GVHD) prophylaxis. Patients with grade II-IV acute GVHD and detectable BKV and JCV viruria developed more HC. In multivariate analysis, higher age remained independent $(p=0.013)$. Patients with $\mathrm{HC}$ experienced longer hospitalization and higher non relapse mortality (NRM). Prostatic hyperplasia (more than $40 \mathrm{~cm}^{\wedge} 3$ ) was found in $33 \%$ of male patients, who developed $\mathrm{HC}$ in $32 \%$ of cases (vs $16 \%$ in patients with smaller prostates, $\mathrm{p}=0.032$ ). In male patients, prostatic volume and age were independent risk factors for $\mathrm{HC}$ ( $p=0.016$ both).

CONCLUSIONS Age is the major risk factor for $\mathrm{HC}$, with a possible role for cyclophosphamide based GVHD prophylaxis and HLA mismatch. In male population, prostatic hyperplasia is an independent additional risk. As $\mathrm{HC}$ is frequent and associates with prolonged hospitalization, more intensive prophylactic strategies could be considered in high-risk subsets.

\section{Introduction}

Hematopoietic allogeneic stem cell transplantation (HSCT) is a curative cell therapy for patients with several haematological malignancies. Conditioning chemotherapy may consist in a myeloablative (MAC) or a reduced intensity (RIC) regimen, depending on type of diagnosis, stem cells source and general condition of the patients. Different regimens are known to affect duration and depth of cytopenias and in some cases the extension of the disease control ${ }^{1}$. After infusion of stem cells, acute or chronic graft versus host disease (a/c-GVHD) may be observed with different grades of severity. Causes of non relapse mortality (NRM) include multiorgan toxicity, infections and hemorrhages occurring during pancytopenia, and GVHD. Despite usually not fatal, hemorrhagic cystitis (HC) is often observed as a specific toxicity of HSCT. As causes and best treatments for $\mathrm{HC}$ are not unanimously defined, this hemorrhagic complication might still be considered as an unmet medical need which impacts heavily on patients hospitalization.

Incidence of $\mathrm{HC}$ varies between $12.2 \%$ and $36.9 \%$ and median occurrence is within the first 30 days. According to literature, major risk factors for $\mathrm{HC}$ seem have been identified as pediatric age, myeloablative conditioning and haploidentical or mismatch $\mathrm{HLA}^{2-4}$. A comparison among matched and haploidentical or mismatch transplants with regards to HC incidence have been tested in 122 patients 
homogeneously treated with post-transplant cyclophosphamide (PTCY) as GVHD prophylaxis, reinforcing the concept that HLA matching is a risk factor independently from immunosuppressive regimen (Copelan 2019), while in 161 haploidentical transplants, multivariate risk factors for $\mathrm{HC}$ resulted in myelosuppressive conditioning and use of tacrolimus rather than cyclosporine ${ }^{5}$. As far as gender is concerned as a possible risk factor for $\mathrm{HC}$, there is no accordance among studies.

Cyclophosphamide has toxic effects on bladder mucosa. Cyclophosphamide containing conditioning regimens have been reported to be more associated with $\mathrm{HC}^{6}$. Moreover, also cyclophosphamide used as GVHD prophylaxis seems to be associated with frequent $\mathrm{HC}^{7}$, despite its preferred utilization in haploidentical transplants rather than in matched transplants may generate an important bias.

Despite some studies report higher incidence of $\mathrm{HC}$ in non oncologic male population affected by prostatic hypertrophy ${ }^{8}$, there are currently no data available concerning the role of prostatic hypertrophy as a possible risk factor for $\mathrm{HC}$ in the setting of HSCT.

In this real life study we aimed to analyze possible unbalance in incidence, severity and duration of $\mathrm{HC}$ among genders, and the role of prostatic hypertrophy in the development of $\mathrm{HC}$, compared to other most assessed risk factors.

\section{Patients And Methods}

We retrospectively collected data of all 237 consecutive patients who underwent HSCT in our Institution from December 2017 to December 2020. Hematopoietic Cell Transplantation-Comorbidity Index (HCT-Cl) was calculated for all patients at the moment of hospitalization for $\mathrm{HSCT}^{9}$. Almost all patients underwent HSCT for oncological malignancies, while stem cell source derived mainly from matched unrelated and haploidentical donors. These and others patients characteristics are described in Table 1.

The majority of patients $(76 \%)$ received a myeloablative conditioning regimen (MAC), mostly based on a thiotepa-busulfan-fludarabine (TT-Bu-Flu) ${ }^{10}$ or on a fludarabine and $12 \mathrm{~Gy}$ total body irradiation (Flu-TBI) combination, while $24 \%$ of patients received a reduced intensity conditioning (RIC) with fludarabine, cyclophosphamide and 2Gy TBI (Baltimore) or TT-Bu-Flu with reduced doses of busulfan.

Prophylaxis for GVHD was conducted with a triple regimen, with cyclosporine and mycophenolate mofetil associated either with post-transplant cyclophosphamide (PTCY) $(79 \%)$ or methotrexate (18\%). With the exception of severe aplastic anemias, from April 2019 GVHD prophylaxis was homogeneously administered with PTCY for all patients, due to center choice and expertise. Acute and chronic GVHD (aGVHD and cGVHD) was graded according to current criteria 0 to 4 and 0 to 3 , respectively ${ }^{11}$.

Hemorrhagic cystitis was considered as any manifestation of macroscopic hematuria, from pinkish urines to massive emission of clots or acute anemia requiring urgent cauterization or intervention, corresponding to a grade 2 to 4 hematuria according to current literature criteria ${ }^{12,13}$. For BKV and JCV 
determination, a PCR test was performed before conditioning and repeated in cases of urinary symptoms or $\mathrm{HC}$, with the highest-value-ever taken into consideration for statistical analysis.

Prostatic volume and diameters were assessed in males by an expert urologist by revising radiological pre-HSCT imaging when available. Prostatic hyperplasia was radiologically considered of grade 0 when up to $20 \mathrm{cc}$, then it was graded as follows: grade $120-40 \mathrm{~cm}^{\wedge} 3$, grade $240-60 \mathrm{~cm}^{\wedge} 3$, grade $360-80$ $\mathrm{cm}^{\wedge} 3$, grade 4 for more than $80 \mathrm{~cm}^{\wedge} 3$ in volume ${ }^{14}$.

Hemorrhagic cystitis free survival (HC-FS) was counted as time from transplantation to first episode of $\mathrm{HC}$, death or last follow up, censored by occurrence of $\mathrm{HC}$.

Patient related risk factors, namely age, gender, HCT-Cl and prostatic volumes in male patients, as well as procedure specific risk factors as HLA matching, GVHD prophylaxis and conditioning regimen, were analyzed in univariate and in multivariate analysis for being associated with higher and earlier incidence of $\mathrm{HC}$ with a Cox analysis. Parametric and non parametric categorical variables as well as continuous variables association with $\mathrm{HC}$-FS were tested with Cox regression both for uni and multivariate analysis, censored by occurrence of HC. Differences in medians were evaluated with Welch's test for unequal variances and Student's T test. Survivals were analyzed with Kaplan Meier's curves and non relapse mortality (NRM) was calculated with Cumulative Incidence method. Statistical analysis was performed with NCSS Statistical Software.

\section{Results}

The median onset of $\mathrm{HC}$ was day 8 after stem cells infusion. Median age was higher in patients experiencing $\mathrm{HC}$ ( 55 vs 61.5 years, $p=0.002$ ). When setting a cutoff up to 55 years, in accordance with the median age of our population, we found an increased risk of $\mathrm{HC}$ for elderly patients $(6 \%$ vs $26 \%, p<$ 0.001). Male patients developed HC in $21 \%$ of cases, compared to $11 \%$ of females $(p=0.03)$. At day 30 , HC-FS was consistently better for females compared to males ( $91 \%$ vs $80 \%, p=0.03)$, with a plateau after the first month.

The great majority of patients underwent HSCT for hematological malignancies, with different onsets of HC showed in Table 1. HC occurred in $15 \%$ patients affected by acute malignancies and in $22 \%$ patients affected by chronic diseases as myeloproliferative neoplasms and lymphomas $(p=0.19)$. There was no difference in incidence of $\mathrm{HC}$ according to $\mathrm{HCT}-\mathrm{Cl}$. We observed poorer $\mathrm{HC}$-FS in patients receiving RIC than MAC ( $14 \%$ vs $25 \%, p=0.03)$. As a notice, patients treated with Flu-TBI MAC regimen experienced no $\mathrm{HC}$ : in this subset, all patients were affected by ALL, and aged 45 years or less.

We then compared HC in HLA identical (sibling and unrelated) vs haploidentical transplants, finding more $\mathrm{HC}$ in the latter $(12 \%$ vs $28 \%, \mathrm{p}<0.001)$. In detail, the incidence of $\mathrm{HC}$ was $6 \%, 15 \%$ and $28 \%$ for sibling, matched unrelated and haploidentical donors, respectively. 
Patients who received GVHD triple prophylaxis with PTCY experienced HC in $20 \%$ of cases, compared to $2 \%$ of $\mathrm{HC}$ in patients who received triple GVHD prophylaxis with MTX $(p=0.02)$. As two out of five patients with severe aplasia experienced $\mathrm{HC}$, we found $40 \% \mathrm{HC}$ in this setting.

In multivariate analysis, age more than 55 alone remained an independent risk factor for $\mathrm{HC}$, with an Hazard Ratio (HR) of 3.06 (95\% Cl 1.26-7.39).

Overall, $195(82 \%)$ and 39 (18\%) patients experienced grade 0-1 or 2-4 acute GVHD, respectively. Patients with grade 0-1 aGVHD had less HC compared to those with grade $2-4$ aGVHD $(13 \%$ vs $29 \%, \mathrm{p}=$ 0.011).

We tested 219 patients for BKV and JCV viruria, which was found positive, anytime during hospitalization, in $18 \%$ and $39 \%$ of cases, respectively. Patients with no viral reactivation had less $\mathrm{HC}$ compared to those with detectable BKV or JCV in urines (15\% vs $33 \% p=0.006$ for BKV and $13 \%$ vs $25 \%$ $p=0.022$ for JCV). Among the 29 patients with both BKV and JCV found positive in urines, $12(41 \%)$ experienced HC. We found no correlation between prostati hyperplasia and detection of BKV or JCV in urines.

Median duration of $\mathrm{HC}$ was 7 days (range 1-85 days): treatment for $\mathrm{HC}$ consisted in adequate hydration and platelets transfusions for all patients; some patients required more intensive treatments consisting in continuous bladder irrigation (55\% of HC), specific antiviral therapy with cidofovir (7\%), endoscopic diathermocoagulation (10\%) or intravesical instillations with Platelet-Rich Plasma (3\%) or hyaluronic acid (3\%). Non relapse mortality was significantly higher for patients with $\mathrm{HC}(\mathrm{p}=0.001)$, both six month ( $8 \%$ vs $25 \%$ ) and one year (12\% vs $38 \%$ ) after transplant (Fig. 1). For those who were successfully discharged, median duration of hospitalization was higher for those with $\mathrm{HC}$ ( 26 vs 36 days, $p=0.05$ ).

We than moved to analyze male population in order to assess the possible role of prostatic volumes. Age more than 55 was confirmed to be associated with higher HC $(p<0.001)$, together with HLA mismatch ( $p$ $=0.008)$ and PTCY based triple GVHD prophylaxis $(p=0.04)$.

Median prostatic volume was greater in patients who experienced $\mathrm{HC}\left(25\right.$ vs $\left.32 \mathrm{~cm}^{\wedge} 3, \mathrm{p}=0.02\right)$. Patients with at least grade 2 prostatic hyperplasia (more than $40 \mathrm{~cm}^{\wedge} 3$ ) experienced $\mathrm{HC}$ in $32 \%$ of cases, compared to $16 \%$ in those with prostatic volume less than $40 \mathrm{~cm}^{\wedge} 3(p=0.03)$. As expected, age and prostatic volume were strongly correlated $(p<0.001)$. In multivariate analysis age over 55 and prostatic volume remained the only independent risk factors for $\mathrm{HC}(p=0.016$ both).

\section{Discussion}

In HSCT patients, hematuria is generally considered related to toxic or infectious impairment of urinary mucosae until proven otherwise, and "hematuria" and "hemorrhagic cystitis" are widely used as synonyms.In this study we aimed to verify the risk potential of patients and transplants characteristics in the development of $\mathrm{HC}$. 
In our cohort, $\mathrm{HC}$ was strongly associated to age both as a continuous increasing risk and with a cut off of at 55 years. The widest available retrospective analysis performed on 1321 patients of all ages identified age lower than 20 years old as being at higher risk of $\mathrm{HC}^{13}$, whether the biggest prospective study on 450 patients did not found differences in $\mathrm{HC}$ from being younger or older than 18 years, despite an incidence of $\mathrm{HC}$ in $21 \%$ of younger patients compared to an average of $12.2 \%{ }^{3}$. At the best of our knowledge, there is no other data analyzing the older age as a risk factor for $\mathrm{HC}$ in an exclusively adult population.

Cyclophosphamide has been described as having a role in HC when used in conditioning regimens ${ }^{13}$. The rationale of this association lies in acrolein, a cyclophosphamide urinary metabolite with toxic effects on bladder mucosae. As some data are available on risk of HC in PTCY treated patients, no comparison has been made between the two triple prophylaxis regimens with post-transplant methotrexate or cyclophosphamide until now. In our population, we report that PTCY treated patients experience more $\mathrm{HC}$, despite not independently from age.

Moderate-to-severe aGVHD was associated to more HC in our population, in partial disagreement to what had been described in 2015 in a small French cohort, where 22 out of 33 haploidentical transplants treated with PTCY experienced HC with no association with GVHD ${ }^{7}$. It is possible to hypothesize a role for GVHD in damaging urothelium together with direct or indirect effects of GVHD therapy with high dose steroids and immunosuppression.

Matched transplants had a lower incidence of HC compared to haploidentical transplants. This is similar to what Copelan and colleagues had described in 122 patients uniformly treated with PTCY prophylaxis, where they reported $\mathrm{HC}$ in $25 \%$ vs $42 \%$ of HLA matched and haploidentical transplants, respectively. In that series the authors hypothesized that HLA mismatched donor T cells could impair host antigen presenting cells, thus favoring BKV infections ${ }^{4}$. A strong association between $\mathrm{HC}$ and BKV detection has been found also in our cohort of patients and was independent from the other risk factor (data not shown). Similarly, Oltolini et al have reported 235 patients who received PTCY as GVHD prophylaxis, where HLA mismatch was found to favor early viral, but not bacterial, infections ${ }^{15}$. As this immunological thesis appears interesting, it does not fully explain higher impact of HLA mismatch in BKV negatives HCs.

About the role of gender in development of $\mathrm{HC}$, few and contrasting literature is available: Gargiulo et al found no difference in $\mathrm{HC}$ incidence in a prospective population of 450 mixed pediatric and adult patients of both genders (13\% vs 11\%), while Lunde et al retrospectively revised 1321 consecutive patients and found that male gender was associated with higher incidence of $\mathrm{HC}(15 \% \mathrm{vs} 23 \%, \mathrm{p}=0.01)^{3,13}$ In our study, male patients had doubled incidence of HC compared to females. We found that HC was more common as prostatic volume increased and that a cut off of $40 \mathrm{~cm}^{\wedge} 3$ was able to discriminate two populations with very different $\mathrm{HC}$ risk $(16 \%$ vs $32 \%, \mathrm{p}=0.03)$. Despite association between age and prostatic hyperplasia results obvious, they seem to remain independently associated to $\mathrm{HC}$ in multivariate analysis. We argued that prostate may play a part in determining incidence and severity of HC in male 
patients. Our hypothesis was that toxic metabolites as acrolein may have a prolonged contact with bladder mucosae due to urinary retention in patients with prostatic hyperplasia. This exposure could reasonably contribute to chemical damage and bleeding in a thrombocytopenic and immunocompromised patient. Moreover, urinary retention may enhance viral damage from JCV and BKV on urothelium. Prostatic samples from patients with prostate cancer (PC) and prostatic hyperplasia have been found to be a reservoir both of BKV and JCV in $22-32 \%$ cases as well as a possible site of viral replication ${ }^{16,17}$. As urinary viral reactivation, especially $B K V$, are common in several immunodeficiency status, and polyomavirus in urinary tract may contribute to $\mathrm{HC}$, it is reasonable to hypothesize that prostatic hyperplasia, viral reactivation and $\mathrm{HC}$ may be connected ${ }^{18,19}$.

Patients with $\mathrm{HC}$ had worse outcomes. Not only they experienced more prolonged hospitalization, but they also had higher probability of dying for NRM. Prolonged hospitalization was usually due to HC, as far as its acute management requires invasive procedures and an intense transfusion support. On the other side, multi organ worsening condition may associate with infections, severe cytopenia or renal failure, thus identifying $\mathrm{HC}$ as the top of an iceberg.

A point of discussion is $\mathrm{HC}$ prophylaxis: from GITMO prospective experience and ECIL guidelines on BKV related HC, some prophylactic approaches have been recommended despite no clear efficacy have been demonstrated. In those papers, Mesna associated to cyclophosphamide, urine alkalinization, intravenous hyper-hydration and bladder continuous irrigation are considered, while no clear position is taken on antibiotic prophylaxis ${ }^{3,20}$. In 2008 Hadjibabaie et al performed continuous bladder irrigation on 40 consecutive patients receiving HSCT for sibling donor and conditioning including cyclophosphamide, and were compared to an historical cohort. Incidence of $\mathrm{HC}$ was $50 \%$ in historical cohort vs $32 \%$ in patients receiving prophylactic irrigation $(p=0.1)$, with lower length of $\mathrm{HC}$ when occurred ( 18 vs 10 days) ${ }^{21}$. In our population, three patients received continuous bladder irrigation for a history if intolerance to Mesna or previous $\mathrm{HC}$, and none of them experienced $\mathrm{HC}$. At present days, treatment of $\mathrm{HC}$ is not formally standardized in the setting of allogeneic transplants, although factors as time from transplant and platelets recovery seem to play a central role.Most patients usually receive intravenous hyper-hydration and intensive platelets transfusion, with continuous bladder irrigation limited to $12-27 \%$ patients according to different experiences ${ }^{13,20}$. Limited amount of patients require intravesical cauterization or intravesical instillation of hyaluronic acid, fibrin glue or platelet-rich plasma. When viral BKV is detected, systemic or local specific therapy is required and can be curative in up to $70 \%$ cases. A possible role may be played by BKV genotype, while the role of JCV need to be further investigated ${ }^{22,23}$.

Data on prostatic hyperplasia have never been reported in this setting:a prospective evaluation of post void residual urine and measurement of acrolein and viruses in urines may clarify the pathogenesis of this complication.

In conclusion, age more than 55 is the an independent risk factor for hemorrhagic cystitis in patient treated with allogeneic stem cell transplantation. Mismatch transplants and PTCY based triple GVHD prophylaxis may have a role, but not independently from age. For male patients, prostatic hypertrophy 
may be an additional risk factor. More intense prophylactic strategies may represent a reasonable option to prevent $\mathrm{HC}$ in the setting of high risk adult transplants.

\section{Declarations}

Funding: The authors acknowledge the support of "Centro di Ricerca sulle cellule staminali emopoietiche e le terapie cellulari "Università Cattolica del Sacro Cuore, Roma" for providing funding for Statistical Software. Authors declare no other funding.

Conflicts of interest/Competing interests: the authors declare no relevant conflict of interests nor competing interests

Availability of data and material: for access to data, please contact the corresponding author.

Code availability: Analysis were performed via NCSS Statistical Software

Authors' contributions: EG FS LDG and SS designed the study and drafted the paper. EM SG EG LDG FS $A M L P C$ and $A B$ provided clinical data. LL II AA SS and AB critically reviewed the paper

Ethics approval: This study has been performed in accordance with the ethical standards of the 2000 Declaration of Helsinki as well as the 2008 Declaration of Istanbul

Consent to participate All patients had provided written informed consent for non interventional research utilization of their anonymized data.

Consent for publication: not applicable (no personal images)

\section{References}

1. Solomon SR, St Martin A, Shah NN et al (2019) Myeloablative vs reduced intensity T-cell-replete haploidentical transplantation for hematologic malignancy. Blood Adv 3(19):2836-2844. doi:10.1182/bloodadvances.2019000627

2. Silva L, de P, Patah, Saliba PA (2010) RM, et al. Hemorrhagic cystitis after allogeneic hematopoietic stem cell transplants is the complex result of BK virus infection, preparative regimen intensity and donor type. Haematologica 95(7):1183-1190. doi:10.3324/haematol.2009.016758

3. Gargiulo G, Orlando L, Alberani F et al. Haemorrhagic cystitis in haematopoietic stem cell transplantation (HSCT): A prospective observational study of incidence and management in HSCT centres within the GITMO network (Gruppo Italiano Trapianto Midollo Osseo).

Ecancermedicalscience. 2014;8(1). doi:10.3332/ecancer.2014.420

4. Copelan OR, Sanikommu SR, Trivedi JS et al (2019) Higher Incidence of Hemorrhagic Cystitis Following Haploidentical Related Donor Transplantation Compared with Matched Related Donor Transplantation. Biol Blood Marrow Transplant 25(4):785-790. doi:10.1016/j.bbmt.2018.12.142 
5. Rimondo A, Crocchiolo R, El-Cheikh J et al (2017) The calcineurin inhibitor and the intensity of the conditioning regimen may affect the occurrence of polyomavirus-associated hemorrhagic cystitis after haploidentical hematopoietic stem cell transplantation with post-transplant cyclophosphamide. Bone Marrow Transplant 52(1):135-137. doi:10.1038/bmt.2016.193

6. Manikandan R, Kumar S, Dorairajan LN (2010) Hemorrhagic cystitis: A challenge to the urologist. Indian J Urol 26(2):159-166. doi:10.4103/0970-1591.65380

7. Ruggeri A, Roth-Guepin G, Battipaglia $G$ et al (2015) Incidence and risk factors for hemorrhagic cystitis in unmanipulated haploidentical transplant recipients. Transpl Infect Dis 17(6):822-830. doi:10.1111/tid.12455

8. Peterson LM, Reed HS. Hematuria (2019) Prim Care - Clin Off Pract 46(2):265-273. doi:10.1016/j.pop.2019.02.008

9. Sorror ML, Maris MB, Storb R et al (2005) Hematopoietic cell transplantation (HCT)-specific comorbidity index: A new tool for risk assessment before allogeneic HCT. Blood 106(8):2912-2919. doi:10.1182/blood-2005-05-2004

10. Sora F, Grazia C, Di, Chiusolo P et al (2020) Allogeneic Hemopoietic Stem Cell Transplants in Patients with Acute Myeloid Leukemia (AML) Prepared with Busulfan and Fludarabine (BUFLU) or Thiotepa, Busulfan, and Fludarabine (TBF): A Retrospective Study. Biol Blood Marrow Transplant 26(4):698703. doi:10.1016/j.bbmt.2019.12.725

11. Jagasia MH, Greinix HT, Arora M et al (2015) National Institutes of Health Consensus Development Project on Criteria for Clinical Trials in Chronic Graft-versus-Host Disease: I. The 2014 Diagnosis and Staging Working Group Report. Biol Blood Marrow Transplant 21(3):389-401.e1. doi:10.1016/j.bbmt.2014.12.001

12. Droller MJ, Saral R, Santos G (1982) Prevention of cyclophosphamide-induced hemorrhagic cystitis. Urology 20(3):256-258. doi:10.1016/0090-4295(82)90633-1

13. Lunde LE, Dasaraju S, Cao Q et al (2015) Hemorrhagic cystitis after allogeneic hematopoietic cell transplantation: Risk factors, graft source and survival. Bone Marrow Transplant 50(11):1432-1437. doi:10.1038/bmt.2015.162

14. Ramsamy K, Subramaniyan R, Patra AK (2016) An observational study of the association between androgenetic alopecia and size of the prostate. Int J Trichology 8(2):62-66. doi:10.4103/09747753.188034

15. Oltolini C, Greco R, Galli L et al (2020) Infections after Allogenic Transplant with Post-Transplant Cyclophosphamide: Impact of Donor HLA Matching. Biol Blood Marrow Transplant 26(6):11791188. doi:10.1016/j.bbmt.2020.01.013

16. Delbue S, Matei DV, Carloni C et al (2013) Evidence supporting the association of polyomavirus BK genome with prostate cancer. Med Microbiol Immunol 202(6):425-430. doi:10.1007/s00430-0130304-3

17. Zambrano A, Kalantari M, Simoneau A, Jensen J, Villarreal L (2002) Detection of human polyomaviruses and papillomaviruses in prostatic tissue reveals the prostate as a habitat for 
multiple viral infections. Prostate 53(4):263-276. doi:10.1002/PROS.10157

18. Markowitz R, Thompson H, Mueller J, Cohen J, Dynan W (1993) Incidence of BK virus and JC virus viruria in human immunodeficiency virus-infected and -uninfected subjects. J Infect Dis 167(1):1320. doi:10.1093/INFDIS/167.1.13

19. Imlay H, Xie H, Leisenring W et al (2020) Presentation of BK polyomavirus-associated hemorrhagic cystitis after allogeneic hematopoietic cell transplantation. Blood Adv 4(4):617-628. doi:10.1182/BLOODADVANCES.2019000802

20. Cesaro S, Dalianis T, Rinaldo CH et al (2018) ECIL guidelines for the prevention, diagnosis and treatment of BK polyomavirus-associated haemorrhagic cystitis in haematopoietic stem cell transplant recipients. J Antimicrob Chemother 73(1):12-21. doi:10.1093/jac/dkx324

21. Hadjibabaie M, Alimoghaddam K, Shamshiri AR et al (2008) Continuous bladder irrigation prevents hemorrhagic cystitis after allogeneic hematopoietic cell transplantation. Urol Oncol Semin Orig Investig 26(1):43-46. doi:10.1016/j.urolonc.2006.12.015

22. Mischitelli M, Fioriti D, Anzivino E et al (2010) Viral infection in bone marrow transplants: Is JC virus involved? J Med Virol 82(1):138-145. doi:10.1002/jmv.21558

23. Fioriti D, Degener AM, Mischitelli M et al (2005) BKV infection and hemorrhagic cystitis after allogeneic bone marrow transplant. Int J Immunopathol Pharmacol 18(2):309-316. doi:10.1177/039463200501800213

\section{Tables}

Table 1: Characteristics of patients of both genders with uni and multi-variate analysis for HC.

Major hematological and demographic characteristics of patients are shown in this table and compared to HC-FS through Cox analysis. Only variables with univariate $p$ values of 0.05 or less acceded to multivariate analysis.

Legend: AML acute myeloid leukemia; ALL acute lymphoid leukemia; MPD myeloproliferative neoplasm; NHL non Hodgkin lymphoma; HL Hodgkin lymphoma; AA aplastic anemia; MDS myelodysplastic syndrome; HCT-Cl Hematopoietic cell transplantation-specific comorbidity index; MSD matched sibling donor; MUD matched unrelated donor; TT-Bu-Flu tepadine, busulfan and fludarabine; Flu-TBI Fludarabine and Total Body Irradiation; GVHD graft versus host disease; MTX methotrexate; PTCY post transplant cyclophosphamide.

\section{Figures}




\begin{tabular}{|c|c|c|c|c|c|c|c|}
\hline & & Patients & $\begin{array}{l}\text { Without } \\
\text { HC }\end{array}$ & $\begin{array}{l}\text { With } \\
\mathrm{HC}\end{array}$ & $\begin{array}{l}\text { Univariate } \\
\text { analysis }\end{array}$ & $\begin{array}{l}\text { Multivariate } \\
\text { analysis }\end{array}$ & $\begin{array}{l}\mathrm{HR} \\
(95 \% \mathrm{ci})\end{array}$ \\
\hline & & & $n(\%)$ & $n(\%)$ & p value & $p$ value & \\
\hline Total & & 237 & $\begin{array}{l}197 \\
(83)\end{array}$ & $\begin{array}{l}40 \\
(17)\end{array}$ & & & \\
\hline \multirow[t]{7}{*}{ Diagnosis } & AML & 101 & $84(83)$ & $\begin{array}{l}17 \\
(17)\end{array}$ & & & \\
\hline & ALL & 30 & $27(90)$ & $\begin{array}{l}3 \\
(10)\end{array}$ & & & \\
\hline & MPN & 54 & $41(75)$ & $\begin{array}{l}13 \\
(25)\end{array}$ & & & \\
\hline & NHL & 17 & $15(88)$ & $\begin{array}{l}2 \\
(12)\end{array}$ & & & \\
\hline & HL & 3 & $3(100)$ & $\begin{array}{l}0 \\
(0)\end{array}$ & & & \\
\hline & AA & 5 & $3(60)$ & $\begin{array}{l}2 \\
(40)\end{array}$ & & & \\
\hline & MDS & 27 & $24(89)$ & $\begin{array}{l}3 \\
(11)\end{array}$ & & & \\
\hline \multirow[t]{2}{*}{$\begin{array}{l}\text { Chronic vs } \\
\text { Acute diseases }\end{array}$} & $\begin{array}{l}\text { LH LNH } \\
\text { MPN AA }\end{array}$ & 79 & $62(78)$ & $\begin{array}{l}17 \\
(22)\end{array}$ & \multirow[t]{2}{*}{0.19} & & \\
\hline & $\begin{array}{l}\text { AML ALL } \\
\text { MDS }\end{array}$ & 158 & $\begin{array}{l}135 \\
(85)\end{array}$ & $\begin{array}{l}23 \\
(15)\end{array}$ & & & \\
\hline \multirow[t]{3}{*}{ HCT-Cl } & $\begin{array}{l}\text { Missing } \\
\text { data }\end{array}$ & 7 & & & \multirow[t]{3}{*}{0.33} & & \\
\hline & $0-1$ & 67 & $58(87)$ & $\begin{array}{l}9 \\
(13)\end{array}$ & & & \\
\hline & $>1$ & 163 & $\begin{array}{l}133 \\
(82)\end{array}$ & $\begin{array}{l}30 \\
(18)\end{array}$ & & & \\
\hline \multirow[t]{3}{*}{ Recipient age } & median & 56 & 55 & 61.5 & 0.002 & & \\
\hline & Up tp 55 & 109 & $\begin{array}{l}102 \\
(94)\end{array}$ & $\begin{array}{l}7 \\
(6)\end{array}$ & \multirow[t]{2}{*}{$<0.001$} & \multirow[t]{2}{*}{0.013} & \multirow[t]{2}{*}{$\begin{array}{l}3.06 \\
(1.26- \\
7.39)\end{array}$} \\
\hline & Over 55 & 128 & $95(74)$ & $\begin{array}{l}33 \\
(26)\end{array}$ & & & \\
\hline \multirow[t]{2}{*}{ Recipient gender } & Females & 102 & $91(89)$ & $\begin{array}{l}11 \\
(11)\end{array}$ & \multirow[t]{2}{*}{0.034} & \multirow[t]{2}{*}{0.25} & \multirow{2}{*}{$\begin{array}{l}1.56 \\
(0.73- \\
3.33)\end{array}$} \\
\hline & Males & 135 & $\begin{array}{l}106 \\
(79)\end{array}$ & $\begin{array}{l}29 \\
(21)\end{array}$ & & & \\
\hline
\end{tabular}




\begin{tabular}{|c|c|c|c|c|c|c|c|}
\hline \multirow[t]{4}{*}{ HLA matching } & MSD & 53 & 50 (94) & $\begin{array}{l}3 \\
(6)\end{array}$ & & & \\
\hline & MUD & 102 & $87(85)$ & $\begin{array}{l}15 \\
(15)\end{array}$ & & & \\
\hline & Haplo & 75 & $54(72)$ & $\begin{array}{l}21 \\
(28)\end{array}$ & & & \\
\hline & CB & 7 & $6(86)$ & $\begin{array}{l}1 \\
(14)\end{array}$ & & & \\
\hline \multirow[t]{2}{*}{$\begin{array}{l}\text { Matched vs } \\
\text { haplo }\end{array}$} & $\begin{array}{l}\text { MSD and } \\
\text { MUD }\end{array}$ & 155 & $\begin{array}{l}137 \\
(88)\end{array}$ & $\begin{array}{l}18 \\
(12)\end{array}$ & \multirow[t]{2}{*}{$<0.001$} & \multirow[t]{2}{*}{0.11} & \multirow{2}{*}{$\begin{array}{l}1.94 \\
(0.86- \\
4.35)\end{array}$} \\
\hline & Haplo & 75 & $54(72)$ & $\begin{array}{l}21 \\
(28)\end{array}$ & & & \\
\hline \multirow{5}{*}{$\begin{array}{l}\text { Conditionning } \\
\text { regimen }\end{array}$} & Missing & 6 & & & & & \\
\hline & TT-Bu-Flu & 190 & $\begin{array}{l}156 \\
(82)\end{array}$ & $\begin{array}{l}34 \\
(18)\end{array}$ & & & \\
\hline & Baltimora & 24 & $19(79)$ & $\begin{array}{l}5 \\
(21)\end{array}$ & & & \\
\hline & Flu-TBI & 17 & $\begin{array}{l}17 \\
(100)\end{array}$ & $\begin{array}{l}0 \\
(0)\end{array}$ & & & \\
\hline & Other & 5 & $3(60)$ & $\begin{array}{l}2 \\
(40)\end{array}$ & & & \\
\hline \multirow[t]{2}{*}{ RIC vs MAC } & MAC & 180 & $\begin{array}{l}154 \\
(86)\end{array}$ & $\begin{array}{l}26 \\
(14)\end{array}$ & \multirow[t]{2}{*}{0.032} & \multirow[t]{2}{*}{0.54} & \multirow{2}{*}{$\begin{array}{l}1.2 \\
(0.62- \\
2.44)\end{array}$} \\
\hline & RIC & 51 & $38(75)$ & $\begin{array}{l}13 \\
(25)\end{array}$ & & & \\
\hline \multirow[t]{2}{*}{$\begin{array}{l}\text { GVHD } \\
\text { prophylaxis }\end{array}$} & $\begin{array}{l}\text { Triple MTX } \\
\text { based }\end{array}$ & 43 & 42 (98) & $\begin{array}{l}1 \\
(2)\end{array}$ & \multirow[t]{2}{*}{0.02} & \multirow[t]{2}{*}{0.068} & \multirow{2}{*}{$\begin{array}{l}6.6 \\
(0.86- \\
47.5)\end{array}$} \\
\hline & $\begin{array}{l}\text { Triple } \\
\text { PTCY } \\
\text { based }\end{array}$ & 188 & $\begin{array}{l}150 \\
(80)\end{array}$ & $\begin{array}{l}38 \\
(20)\end{array}$ & & & \\
\hline
\end{tabular}




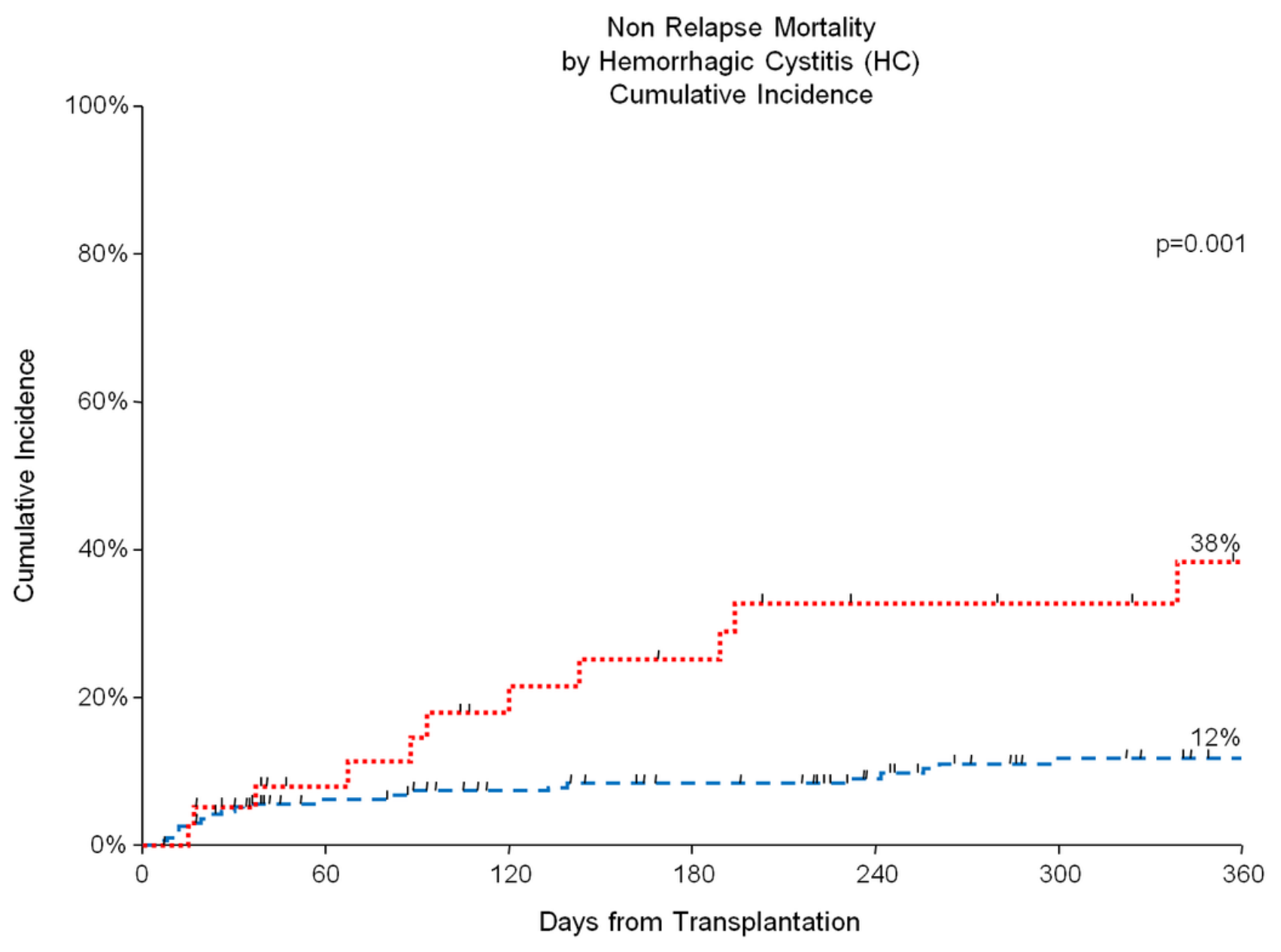

Number At Risk

- - - Without HC 197

40

171

27
150

21
136

18
121

13
106

11
100

7

\section{Figure 1}

Non Relapse Mortality (NRM) and Hemorrhagic Cystitis (HC). Patients with HC (in red) had higher NRM compared to those without $\mathrm{HC}$ (in blue), with $8 \%$ vs $25 \%$ at 6 months and $12 \%$ vs $38 \%$ at 1 year $(p=0.001)$. 